\title{
Short Communication: Hydroperoxides in Circulating Lipids from Dairy Cows: Implications for Bioactivity of Endogenous-Oxidized Lipids
}

\author{
B. Löhrke, ${ }^{1}$ T. Viergutz, ${ }^{1}$ W. Kanitz, ${ }^{1}$ B. Losand, ${ }^{2}$ D. G. Weiss, ${ }^{3}$ and M. Simko ${ }^{3}$ \\ ${ }^{1}$ Research Institute for the Biology of Farm Animals Dummerstorf, Germany \\ ${ }^{2}$ Landesforschungsanstalt Mecklenburg-Vorpommern, Germany \\ ${ }^{3}$ University of Rostock, Institute of Cell Biology, Germany
}

\section{ABSTRACT}

This study was conducted to investigate the potential for increased oxidative stress of high- vs. average-producing dairy cows. Two experiments were performed using 11 and 13 Holstein cows (53 $\pm 2 \mathrm{~d}$ postpartum). Lipohydroperoxides (LHP) were determined in serum lipids (experiment 1) and low-density lipoprotein (experiment 2) via oxidation of ferrous to ferric ions through LHP using thiocyanate as chromogen. In experiment 1, differing milk yield and milk energy output corresponded to different concentrations of LHP. In experiment 2 , analysis of regression resulted in a significant relationship between milk yield and LHP. Phospholipids isolated from lipids with $6.5 \mu M$ of LHP evoked in monocytic cells a transient increase in superoxide formation, indicating inflammatory potential. The results show that high milk productivity can associate with oxidative stress indicated by oxidative modifications of circulating lipids and their changed bioactivity.

(Key words: lipohydroperoxide, oxidative stress, superoxide formation)

Abbreviation key: LDL = low-density lipoprotein, LHP = lipohydroperoxides, PAF = platelet-activating factor, $\mathbf{P L}=$ phospholipids.

Milk energy output has been demonstrated in dairy cows to be a linear function of metabolizable energy intake (Schiemann et al., 1974). This intake correlates with heat production, a measure for oxidative metabolism, which is closely related to the oxygen consumption of the whole body in cattle (Löhrke et al., 1997). An increase in oxygen consumption does not necessarily mean oxidant stress, i.e., an imbalance between formation and detoxification of reactive oxygen metabolites (Behrman et al., 2001). In turn, an increase in oxidative

Received September 24, 2004.

Accepted January 11, 2005.

Corresponding author: B. Löhrke; e-mail: viergutz@ fbn-dummerstorf.de. metabolism corresponds to a higher production of reactive oxygen metabolites at least regarding the activity of the mitochondrial respiratory chain, the main oxygen consumer (Ainscow and Brand, 1999). Some of these metabolites generally escape from endogenous defense mechanisms and may serve both important physiologic and damaging roles (Behrman et al., 2001). Insufficient detoxification is indicated by oxidative modifications, including peroxidation of lipids (Porter et al., 1995). This study was conducted to investigate the potential for increased oxidative stress of high- vs. average-producing dairy cows.

German Holstein cows (experiment $1, \mathrm{n}=11$; experiment $2, \mathrm{n}=13$ ) from the Dummerstorf dairy cattle farm were used at postpartum d $53 \pm 2$, a lactation stage that corresponds to a period of reaching positive energy balance in high-performance cows (Selberg et al., 2004). In experiments 1 and 2, the number of cows in first, second, and third parity was $\mathrm{n}=4$ and 5,3 and 4,4 and 4 , respectively. Cows were offered twice daily ad libitum amounts of TMR (containing a mineral and vitamin mixture) to allow for $10 \%$ orts. In terms of net energy retention (Beyer et al., 2003), the TMR offered $201 \mathrm{MJ} / \mathrm{d}$ (roughages, $58 \mathrm{MJ} / \mathrm{d}$; concentrate, $143 \mathrm{MJ} / \mathrm{d}$ ). Cows were milked 3 times daily, and milk performance records were accomplished by the governmental milk performance control association. The milk productivity results presented refer to an average of 2 consecutive milk performance data from records by the month. Milk energy output was calculated on the basis of daily milk yield and fat percentage using $2.92 \mathrm{MJ} / \mathrm{kg}$ of milk (3.5\% fat) and $0.22 \mathrm{MJ} / \mathrm{kg}$ for increases in fat of $0.5 \%$ (Beyer et al., 2003). Twelve ( \pm 2 ) days following milk performance recording, blood was collected after morning milking before feeding via coccygeal arterio-venipuncture using glass tubes $(10 \mathrm{~mL})$. This procedure was approved by the governmental Animal Care Committee (Mecklenburg-Vorpommern). Blood was placed on ice and transported to our laboratory within $30 \mathrm{~min}$. Serum prepared by centrifugation $\left(3000 \times g, 15 \mathrm{~min}, 4^{\circ} \mathrm{C}\right)$ was treated with butylated hydroxytoluene (to $20 \mu M$ ), an antioxidant, and Pefabloc (to $0.2 \mathrm{mM}$ ) to inhibit deacylation 
Table 1. Milk performance in cows with different concentrations of hydroperoxides in serum lipids.

\begin{tabular}{|c|c|c|c|c|c|c|c|}
\hline \multirow[b]{2}{*}{ Group } & \multirow[b]{2}{*}{ no. } & \multicolumn{2}{|c|}{ Milk yield } & \multicolumn{2}{|c|}{ Milk energy } & \multicolumn{2}{|c|}{ Lipohydroperoxide } \\
\hline & & $\mathrm{kg} / \mathrm{d}$ & SEM & $\mathrm{MJ} / \mathrm{d}$ & SEM & $\mu M$ & SEM \\
\hline I & 5 & 34.2 & 1.0 & 122.2 & 9.8 & 3.6 & 0.45 \\
\hline II & 6 & 51.7 & 3.3 & 164.8 & 11.2 & 6.5 & 0.30 \\
\hline$P^{1}$ & & \multicolumn{2}{|c|}{0.001} & \multicolumn{2}{|c|}{0.021} & \multicolumn{2}{|c|}{0.015} \\
\hline
\end{tabular}

${ }^{1} P$ stands for the result of an unpaired $t$-test among groups per column with a test power $\beta(\alpha=0.05)>$ 0.85 in each case.

of phospholipids; low-density lipoprotein (LDL) was isolated by ultracentrifugation and further purified by precipitation on the analogy of an established technique (Nauck et al., 1995). Lipohydroperoxides (LHP) were determined in serum lipids (experiment 1) or LDL (experiment 2) via reaction of LHP with ferrous ions to produce ferric ions, which were detected by thiocyanate as the chromogen in a deoxygenated organic phase (Mihaljevic et al., 1996) using a kit (Cayman, Alexis Biochemicals, Grünberg, Germany). In experiment 1, polar phospholipids (PL) were isolated by amberlite XAD-2 resin chromatography (Salari, 1986). Phosphorus was measured by a microassay (Ames and Dubin, 1960). Bioactivity of PL was assayed by responses of MonoMac-6 cells (not primed by cytokines), a monocytic cell line (Weber et al., 1993) possessing receptors for the platelet-activating factor (PAF). Formation of superoxide anions was detected through chemiluminescence of lucigenin. Luminescence was calibrated using a xanthine oxidase system (Ohara et al., 1993). Comparisons between 2 groups of animals were performed by unpaired $t$-test. The accepted level of significance was $P$ $<0.05$. Data are reported as the means $( \pm \mathrm{SEM})$ when not otherwise stated. Tests and analysis of linear regression was accomplished by statistical software package (SAS Inst., Inc., Cary, NC and Sigma Stat, Jandel Scientific, Erkrath, Germany).

The results of experiment 1, shown in Table 1, indicate presence of LHP in circulative lipids of dairy cows. These data demonstrate for the first time to our knowledge that cows with lower levels of LHP showed lower milk yield and milk energy output. This relationship was quantified in experiment 2 by an analysis of regression using lipids from LDL, a major oxidative target (Navab et al., 2001). The analysis resulted in the equation: LHP $(\mu M)=-1.95( \pm 0.88)+0.078( \pm 0.022)$ milk yield $(\mathrm{kg} / \mathrm{d}), \mathrm{r}=0.77, P=0.0048$, regarding the slope of the regression line.

Previous studies investigated oxidant status of periparturient dairy cows in relation to placental retention and in response to dietary antioxidants (BrzezinskaSlebodzinska et al., 1994) or to hot season (Bernabucci et al., 2002). Concentrations of plasma antioxidants and activity of glutathione peroxidase in red blood cells corresponded to duration of retained fetal membranes after calving (Brzezinska-Slebodzinska et al., 1994). Erythrocytes were suggested to be a sensitive model to study the oxidative status of transition dairy cows exposed to hot environment. Oxidative markers in plasma did not give unambiguous information (Bernabucci et al., 2002). We did not assess oxidative status, but investigated an outcome of the overproduction of oxidants that exceeded antioxidant capacity. We studied lipids as biological target and preferred direct measurement of LHP to indirect assays. The latter include thiobarbituric acid-reactive substances that measure decomposition products (aldehydes) of oxidized lipids and do not exactly indicate peroxidation of abundant monounsaturated lipids, such as oleic acid that does not produce aldehyde compounds by peroxidation (Mihaljevic et al., 1996). Monounsaturated lipids are oxidized by strong oxidants, including peroxynitrite generated by the reaction between radicals, such as superoxide and nitric oxide, a reaction nearly 3 times faster than the reaction of superoxide with superoxide dismutase (Ischiropoulos et al., 1992; Porter et al., 1995). Polar phospholipids are known to change their bioactivity by oxidation (Marathe et al., 1999). Therefore, we tested the effect of PL extracted from serum lipids on superoxide formation of monocytes. Phospholipids from the lower-producing cows (Table 1; group I) did not significantly evoke superoxide production above basal level (data not shown). However, monocytes responded to PL of group II with a marked transient increase in superoxide formation (Figure 1). The response was similar to superoxide induction through PAF, a proinflammatory PL (Marathe et al., 1999). Responses of both PL and PAF were inhibited by 3-[4-(2-chlorophenyl)-9-methyl-6H-thienol[3,2-f] $(1,2,4)$ triazolo-[4,3-

a] [1,4]-diazepin-2yl]-1-(4-morpholinyl)-1-propanon, a PAF receptor blocker, indicating receptor-mediated (specific) responses. Ligand binding has been reported to cause a rapid down-regulation of these cell surface receptors of monocytes not primed by cytokines (Weber et al., 1993). Metabolic responses that are not mediated by PAF receptors include time-dependent fluctuations 


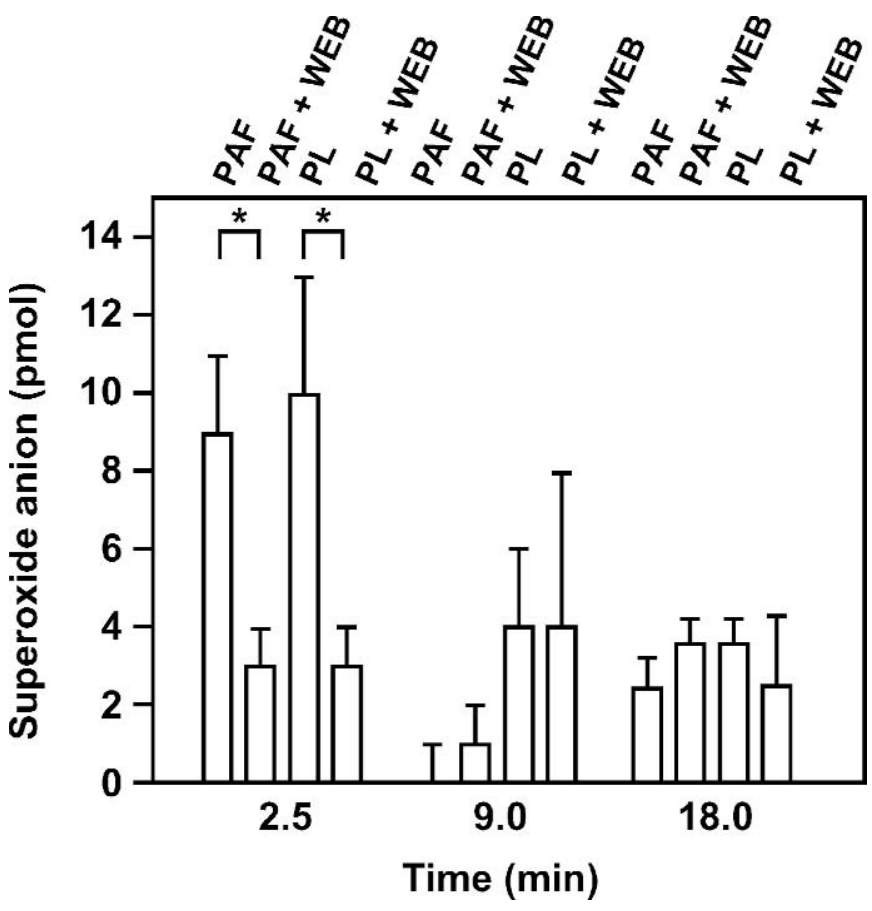

Figure 1. Superoxide anion formation of monocytes in response to phospholipids isolated from serum lipids by cows with a higher concentration of hydroperoxides Group II: $6.5 \mu M$ of lipohydroperoxixdes (LHP)]. The response to phospholipids (PL) from serum lipids with lower LHP concentration Group I: $3.6 \mu M$ of LHP) was not significant; data were not reported. Responses were evoked by platelet-activating factor (PAF; $100 \mathrm{pmol}$ ) and PL (4 nmol of phosphorus) and inhibited by 3-[4-(2-chlorophenyl)-9-methyl- $6 \mathrm{H}$-thienol[3,2f] $(1,2,4)$ triazolo-[4,3-a] [1,4]-diazepin-2yl]-1-(4-morpholinyl)-1propanon (WEB; $10 \mu M$ ).

of basal superoxide formation (Figure 1). In conclusion, the current study demonstrates the presence of LHP in serum from average and high producing cows during an early lactation stage. However, the mechanism involved in changing LHP level remains to be identified. Phospholipids from high-performance cows contain proinflammatory PAF-like lipids. If the responses to those lipids observed in vitro apply to situations in vivo, the results may have implications for animal health and reproduction.

\section{REFERENCES}

Ainscow, E. K., and M. D. Brand. 1999. Top-down control analysis of ATP turnover, glycolysis and oxidative phosphorylation in rat hepatocytes. Eur. J. Biochem. 263:671-685.
Ames, B. N., and D. T. Dubin. 1960. The role of polyamines in the neutralization of bacteriophage deoxyribonucleic acid. J. Biol. Chem. 235:769-775.

Behrman, H. R., P. H. Kodaman, S. L. Preston, and S. Gao. 2001. Oxidative stress and the ovary. J. Soc. Gynecol. Invest. 8:S40-S42.

Bernabucci, U., B. Ronchi, N. Lacetara, and A. Tardone. 2002. Markers of oxidative status in plasma and erythrocytes of transition dairy cows during hot season. J. Dairy Sci. 85:2173-2179.

Beyer, M., A. Chudy, L. Hoffmann, W. Jentsch, W. Laube, K. Nehring, and R. Schiemann. 2003. Pages 10-14 in Rostock Feed Evaluation System. Reference Numbers of Feed Value and Requirement on the Base of Net Energy. Plexus Verlag, Frankfurt, Germany.

Brzezinska-Slebodzinska, E., J. K. Miller, J. D. Quigley, J. R. Moore, and F. C. Madson. 1994. Antioxidant status of dairy cows supplemented prepartum with vitamin E and selenium. J. Dairy Sci. 77:3087-3095.

Ischiropoulos, H., L. Zhu, J. Chen, M. Tsai, J. C. Martin, C. D. Smith, and J. S. Beckman. 1992. Peroxynitrite-mediated tyrosine nitration catalyzed by superoxide dismutase. Arch. Biochem. Biophys. 298:431-437.

Löhrke, B., M. Derno, B. Krüger, T. Viergutz, H. Matthes, and W. Jentsch. 1997. Expression of sulphonylurea receptors in bovine monocytes from animals with a different metabolic rate. Pflügers Arch. 434:712-720.

Marathe, G. K., S. S. Davies, K. A. Harrison, A. R. Silva, R. C. Murphy, H. Castro-Faria-Neto, S. M. Prescott, G. A. Zimmerman, and T. M. McIntyre. 1999. Inflammatory platelet-activating factor-like phospholipids in oxidized low density lipoproteins are fragmented alkyl phosphatidylcholines. J. Biol. Chem. 274:28395-28404.

Mihaljevic, B., B. Katusin-Razem, and D. Razem. 1996. The reevaluation of the ferric thiocyanate assay for lipid hydroperoxides with special considerations of the mechanistic aspects of the response. Free Radic. Biol. Med. 21:53-63.

Nauck, M., K. Winkler, C. Wittmann, H. Mayer, C. Luley, W. März, and H. Wieland. 1995. Direct determination of lipoprotein(a) cholesterol by ultracentrifugation and agarose gel electrophoresis with enzymatic staining for cholesterol. Clin. Chem. 41:731-738.

Navab, M., S. Y. Hanna, G. P. Hough, G. Subbanagounder, S. T. Reddy, and A. M. Fogelman. 2001. A cell-free assay for detecting HDL that is dysfunctional in preventing the formation of or inactivating oxidized phospholipids. J. Lipid Res. 42:1308-1317.

Ohara, Y., T. E. Peterson, and D. G. Harrison. 1993. Hypercholesterolemia increases endothelial superoxide anion production. J. Clin. Invest. 91:2546-2551.

Porter, N. A., S. E. Caldwell, and K. A. Mills. 1995. Mechanisms of free radical oxidation of unsaturated lipids. Lipids 30:277-290.

Salari, H. 1986. Solid-phase extraction and reversed-phase high-performance liquid chromatographic technique for isolation and estimation of platelet activating factor in plasma. J. Chromatogr. 382:89-98.

Schiemann, R., G. Henseler, W. Jentsch, and H. Wittenburg. 1974. Utilization of feed energy for milk production. 8. Determination of energy metabolism in high-yielding cows in the early stage of lactation. Arch. Tierernähr. 24:105-137.

Selberg, K. T., A. C. Lowe, C. R. Staples, N. D. Luchini, and L. Badinga. 2004. Production and metabolic responses of periparturient Holstein cows to dietary conjugated linoleic acid and transoctadecenoic acids. J. Dairy Sci. 87:158-168.

Weber, C., H. J. Kruse, A. Sellmayer, W. Erl, and P. C. Weber. 1993. Platelet activating factor enhances receptor-operated $\mathrm{Ca}(++)$-influx and subsequent prostacyclin synthesis in human endothelial cells. Biochem. Biophys. Res. Commun. 195:874-880. 